\title{
BIOPOLÍTICA COMO CONTROLE SOBRE A VIDA E POLÍTICA DE RESISTÊNCIA
}

\author{
BIOPOLYTICS AS CONTROL OVER \\ LIFE AND POLITICS OF RESISTANCE
}

\section{Joelson Silva Araújo ${ }^{1}$}

\begin{abstract}
Resumo: O objetivo deste artigo é pensar o conceito de biopolítica, a partir de Michel Foucault, considerando duas possibilidades: compreendendo as teorias políticas modernas que consideravam o poder como algo exclusivamente do soberano, exercendo a autoridade sobre o povo, controlando a vida, impondo, assim, políticas para controlar o corpo. Como também outra possibilidade levada em conta é analisar a biopolítica como forma de resistência do sujeito, como política em favor do indivíduo, que resiste ao poder tentando fabricar sua subjetividade. Por fim, é visto uma relação entre a biopolítica e liberdade como uma forma de afirmação do sujeito.

Palavras-chave: biopolítica, biopoder, genealogia, arqueologia, resistência.
\end{abstract}

\begin{abstract}
The aim of this paper is to rethink about the concept of biopolitics, starting from Michel Foucault, considering two possibilities: the understanding modern political theories that considered power as something exclusively exercised by sovereign, exercising authority over the people, controlling life, thus imposing policies to control bodies. Another possibility taken into account is to analyze biopolitics as a form of resistance of the subject, as politics in favor of the individual, who resists power trying to fabricate bis subjectivity. Finally, a relation between biopolitics and freedom is seen as a form of affirmation of the subject.
\end{abstract}

Keywords: biopolitics, biopower, genealogy, archeology, resistance

\section{INTRODUÇÃO}

Michel Foucault, especificamente no ano de 1974, proferindo uma palestra na cidade do Rio de Janeiro, começa a utilizar nos seus estudos o termo "biopolítica", conceito este que se tornaria um dos mais importantes conceitos investigados pelo mesmo até o final da sua vida. O nascimento da medicina social foi o nome do ensaio em que Foucault mencionou pela primeira vez o termo "biopolítica", embora só em 1979, em um curso ministrado no Collège de France, o filósofo francês elaborasse um estudo totalmente voltado para esse campo, o qual foi intitulado de Nascimento da Biopolítica. Foucault define o paradigma biopolítico a partir das práticas de governação modernas, deslocando-se, assim, das teorias clássicas sobre o poder, o Estado e a política, considerando que o poder não se limita à soberania do Estado.

Aristóteles defendia que o ser humano é um animal político, tendo em mente em especial as leis instituídas pelo Estado. Foucault, no entanto, observa esta caracterização apenas como uma pequena parte, uma mera face exterior, ou seja, o poder não está apenas nas determinações de um governo instituído, fazendo com que as pessoas sigam normas, regras ou

${ }^{1}$ Doutorando do Programa de Pós Graduação em Filosofia - PPGFIL - UFRN e professor da rede estadual de ensino do Rio Grande do Norte. Orcid: http://orcid.org/0000-0002-9644-0996 
leis. O poder, na verdade, está em todos os espaços da vida, não é exercido somente por determinados grupos, classes ou instituições. Por isso, para que se começar o estudo do conceito de biopolítica em Michel Foucault é preciso deixar de lado essa concepção de soberania do estado, essa visão de que o poder só está presente nos aparelhos de controle institucional.

Neste trabalho, o que nos ocupará são as seguintes questões: o que é a biopolítica e a partir de que momento histórico pode-se falar que tenha surgido essa forma de se ver o poder, atrelado a todos os aspectos da vida, diferindo-se, assim, da visão política clássica de que o poder está preponderantemente vinculado ao soberano, ao Estado. Outra questão que pode ser sustentada a partir dos textos de Foucault é a de que a biopolítica pode ser vista somente como forma de dominação da sociedade, impondo normas à população, desse modo, controlando-a. Ou, ao contrário, o poder ser visto também como forma de resistência, de protesto e de escape das imposições feitas pelo sistema capitalista. O que nos ocupa aqui é, localizar e refletir mormente sobre essa possível bipartição que o conceito de biopolítica sofre ao longo dos estudos foucaultianos. Localizando e refletindo sobre a origem e pensando por um prisma diferente, visamos analisar outras possibilidades de metamorfoseamento desse conceito.

Foucault, que tem as suas obras indiscutível e constitutivamente formadas a partir da genealogia, método utilizado no século XIX pelo filósofo alemão Friedrich Nietzsche, que é uma busca pelas raízes históricas, por exemplo, de conceitos, de valores, de instituições sociais. Com a genealogia o que se busca mostrar é o que geralmente não é mostrado pela história, ou pela que pode ser considerado a versão "oficial", ou seja, a história que é contada para todos. Na obra Microfísica do Poder, vê-se claramente essa posição relativa ao método genealógico:

A genealogia é cinza, ela trabalha com pergaminhos embaralhados, riscados muitas vezes reescritos [...] Daí, para a genealogia, um indispensável demorar-se: marcar a singularidade dos acontecimentos, longe de toda finalidade monótona; espreitá-los lá onde menos se os esperava e naquilo que é tido como não possuindo história (FOUCAULT, 1979, p.15).

O método genealógico, entretanto, não busca a essência da história, não busca o sentido, ou a história, ou ainda uma única história. Para Foucault, quando se fala em História com "h" maiúsculo, está se defendendo uma história fora do tempo, o que para o filósofo não existe. Assim, o que se busca é uma análise coerente, a partir dos dados, dos documentos, associando a esta investigação muita paciência, para que se reconstrua a coerência dos acontecimentos e da história. Consideramos que Foucault não se desvia desse ao analisar a biopolítica, pois a história do conceito de biopolítica será investigado no seu próprio tempo, considerando todo o contexto que circundou o seu nascimento.

Entretanto, a metodologia empregada por Foucault para realização do estudo sobre a biopolítica não se limita ao método genealógico, na medida em que o filosofo francês também utiliza o que se pode denominar de arqueologia, ou seja, um trabalho de escavação, buscando na história, por meio de documentos, para analisar as práticas discursivas, e saber como se constituíram todas essas práticas discursivas que se encontram na política moderna, para tanto, o nosso empreendimento exige que se saiba identificar essa nuance que circunda todo o estudo de Michel Foucault. Desse modo, nas obras de Foucault não é apenas apresentada uma perspectiva filosófica, tornando-se mais abrangente, por envolver outras áreas do saber, tais como a sociologia e a própria história, destarte podemos dizer que a análise da biopolíti-

PRACS: Revista Eletrônica de Humanidades do Curso de Ciências Sociais da UNIFAP https://periodicos.unifap.br/index.php/pracsISSN 1984-4352Macapá, v. 12, n. 1, p. 145-152, jan./jun. 2019 
ca é apresentada a partir de perspectiva histórico-filosófico-social.

\section{O NASCIMENTO DA BIOPOLÍtiCA E A ASCENSÃo DO PODER ECONÔMICO}

Foucault observa que, ao longo dos séculos XVI, XVII, até meados do século XVIII, existia toda uma série de práticas, consideradas governamentais, exercidas pelo soberano, como, por exemplo: as cobranças de impostos, de tarifas alfandegárias, as regulações sobre todo o processo de fabricação, os regulamentos sobre as tarifas dos cereais, dentre muitas outras práticas que compunham o conjunto de atribuições do estado e que eram vistos como o pleno exercício do direito soberano, e, dentre esses direitos estava várias técnicas para a permanência dos costumes, para impedir as revoltas por parte da população. A partir de meados do século XVIII, com o liberalismo, apontado, por Foucault, como uma nova forma de governar, é que se pode começar a investigar o que é a biopolítica. É a partir desse contexto que aparece, no interior da razão governamental, uma verdade econômica, verdade essa que se coloca contra, ou faz oposição, à razão de estado, é por isso que na obra Nascimento da Biopolitica,Foucault afirma:

Se se compreender bem o que estáem causa nesse regime que é o liberalismo, o qual se opõe a razão de Estado, ou antes, [a] modifica fundamentalmente sem talvez questionar seus fundamentos. Só depois que soubermos o que era esse regime governamental chamado liberalismo é que poderemos, parece-me, apreender o que é a biopolítica (FOUCAULT, 2008, p. 30).

Assim, torna-se muito importante, para a investigação sobre o nascimento da biopolítica, entender como se constitui o liberalismo. No século XVIII surge a teoria econômica do liberalismo, tendo como principal expoente o teórico escocês Adam Smith (1723 - 1790). A teoria econômica liberalista preconizava que há leis próprias inerentes ao processo econômico, exemplo disso é a lei da oferta e da procura, que é responsável pelo equilíbrio entre a produção, a distribuição e o consumo de bens em uma sociedade. No interior do discurso liberalista está presente algo novo ou, pode-se dizer, algo que ainda não havia sido enfatizado a partir da segunda metade do século XVIII, uma ideia contrária, inclusive, às teorias políticas clássicas, de que o poder não está somente nas mãos do soberano, ou do governante.

A verdade também não será apenas atribuída ao soberano, mas sim ao mercado. Segundo Foucault, até o início do século XVIII, o mercado era considerado como lugar de jurisdição, ou seja, um lugar de justiça, local esse que era controlado através de normas para que os produtos não ficassem fora da qualidade, para que os preços fossem regulados corretamente e também um espaço em que o comprador seria protegido. Foucault diz que, a partir do final do século XVIII, o mercado torna-se o "lugar da veridição", o mercado, de certa forma, passa a ser o principal governante, o responsável até mesmo pela prática governamental, passando a determinar a verdade. Entretanto, Foucault afirma que o regime de veridição não pode ser caracterizado por uma determinada lei que possui toda a verdade, ela faz parte de todo conjunto regrado para estabelecer, sempre seguindo certo discurso, quais questões devem ser consideradas como verdadeiras ou como falsas.

É nesse cenário histórico em que se dá o nascimento da biopolítica, marcado por essa mudança na forma de governar. A partir desse momento, mais especificamente do século XVIII, as disciplinas se voltam para os indivíduos, e, principalmente, para os seus corpos, 
pois o corpo é o alvo principal do adestramento realizado por intermédio das diversas instituições que o indivíduo se depara ao longo de sua vida, tais como: a escola, o hospital, a própria fábrica. Esta última tem um papel decisivo, contribuindo para normalização dos indivíduos. Inserido, assim, na política econômica, os corpos.

A partir desse momento os corpos serão adestrados segundo o modelo capitalista, o que nos permite afirmar que o biopoder contribui seguramente para o desenvolvimento do próprio capitalismo, pois a população se adéqua aos processos econômicos. Na forma de governo, que Foucault chama de razão de Estado, em que o soberano detém o poder sobre seus súditos, via-se que o poder se estabelecia de tal modo que ao soberano era atribuído o direito de causar a morte e de deixar viver. Já nas sociedades disciplinares esse direito não aparece da mesma maneira, pois o biopoder, ou seja, o poder sobre a vida é visto que a partir do século XVIII como uma preocupação com a mortalidade, a natalidade, permitindo políticas voltadas para o público, por exemplo, a ação sobre epidemias. havendo assim a tentativa de controlar doenças. Foucault afirma:

E é em relação a estes fenômenos que essa biopolítica vai introduzir não somente instituições de assistência (que existem faz muito tempo), mas mecanismos muito mais úteis, economicamente muito mais racionais do que a grande assistência, a um só tempo maciça e lacunar, que era essencialmente vinculada a igreja (FOUCAULT, 1999, p. 291).

Nesta senda, vê-se pairar que o objetivo é o controle sobre a vida, organizando-a através das instituições, o que inclui formas de vigiar, de majorar, para que tudo e todos estejam organizados segundo o sistema capitalista. Não se trata mais de pensar uma deliberação que vise à morte, e sim formas para controlar a vida: assim nasce a biopolítica.

\section{A BIOPOLÍTICA COMO POLÍTICA DE RESISTÊNCIA}

Até agora, viu-se que a biopolítica nasce dentro de um sistema, o liberalismo, e que esse sistema apresenta em seu cerne uma política econômica, que visa controlar o corpo do indivíduo e adestrar a população através das instituições presentes nas sociedades disciplinares. Contudo, essa é apenas uma face do conceito de "biopolítica", sendo ele passível de metamorfoses e interpretações, entre elas está uma, contrária e diferente. Primeiramente, pode-se dizer que essa hipótese metamorfoseia o primeiro sentido que foi dado à biopolítica, apresentado anteriormente. Agora, a questão que surge é a seguinte: a biopolítica pode se apresentar como política de resistência, assumindo um caráter crítico a favor do indivíduo? A investigação sobre essa hipótese se mostra como contraponto em relação ao nascimento da biopolítica, pois ela nasce através de práticas criadas para controlar o corpo, partindo de um poder político e econômico. A partir dessa hipótese, podemos pensar o contrário, quer dizer, que a biopolítica pode ser pensada como um instrumento de resistência às práticas de poder sobre o corpo, à fabricação de subjetividade? Sobre o termo "resistência", presente nos estudos de Foucault a partir da década de 70, segundo Judith Revel ${ }^{2}$ afirma:

${ }^{2}$ Doutora emhistória dopensamentocontemporâneo, Ph.D.,um especialistaempensamentofrancêscontemporâneo. Depoisde muitos anosnaItália, JudithRevel, actualmente, lecciona na UniversidadedeParisIepesquisadorassociado doLaboratório deAntropologiaIIAC.

PRACS: Revista Eletrônica de Humanidades do Curso de Ciências Sociais da UNIFAP https://periodicos.unifap.br/index.php/pracsISSN 1984-4352Macapá, v. 12, n. 1, p. 145-152, jan./jun. 2019 
O termo resistência aparece, então, a partir dos anos $70 \mathrm{com}$ um sentido bastante diferente daquele que tinha a "transgressão": a resistência se dá, necessariamente, onde há poder, porque ela é inseparável das relações de poder; assim tanto a resistência funda as relações de poder, quanto ela é, às vezes, o resultado dessas relações; na medida em que as relações de poder estão em todo lugar, a resistência é a possibilidade de criar espaços de lutas e de agenciar possibilidades de transformação em toda parte (RAVEL, 2005, p. 74).

Desse modo, o que se quer aqui, é justamente tratar da biopolítica também como resistência, como uma possibilidade de criação de lutas e transformação da sociedade em todos os âmbitos, visto que o poder está em toda parte. No curso Em Defesa da Sociedade, realizado no Collège de France entre 1975 e 1976, nota-se a preocupação de Foucault com questões referentes ao poder, discorrendo de maneira muito crítica e pensando não somente no poder como forma de assujeitar a sociedade, mas também como instrumento de resistência e de criação de outras subjetividades. A biopolítica pode ser pensada em outro sentido, como diz Benjamim:

Por outro lado, podemos ainda afirmar que esses conceitos têm uma origem um pouco mais distante ou anterior à genealogia, na medida em que a biopolítica apresenta outra face, que não é mais a face cavernosa, escura, da colonização, da dominação que fabrica, normaliza a vida dos indivíduos, mas ela pode ser pensada como uma postura crítica, uma insubmissão diante das servidões, dos conservadorismos e essa postura, essa insubmissão, essa vontade de não ser governado, de não ser categorizado já está presente em Foucault antes mesmo de seu encontro com o método Nietzsche (a genealogia) (BENJAMIN, 2010, p. 38).

É neste viés que se pretende abordar, a partir deste ponto em diante, o conceito de "biopolítica", que não se revela com a obra Nascimento da biopolítica, que data de 1978-1979, e sim, é visto já esse conceito a partir de 1974 e 1975, especialmente ao mostrar essa outra visão da biopolítica como política de resistência. Alguns comentadores das obras foucaultianas, como Leonora Corsini e também Judith Revel, defendem que no início da década de 70, Foucault falava, sem fazer diferenciações, sobre o biopoder e a biopolítica. Entretanto, em 75, essa posição muda, na medida em que o filósofo começa a distinguir ambos os conceitos, dando ao biopoder o sentido de poder sobre a vida, e à biopolítica, que começa a ser pensada não somente como forma de poder centrado na exploração dos indivíduos, mas como uma resistência que se apresenta como resposta da vida, contrária a esses poderes.

O que se deve arrostar aqui é que, o poder não se apresenta e se instala facilmente e amigavelmente, deixando todos cheios de júbilo, tendo como primado a concórdia. O poder sempre encontra resistências, discordâncias e, principalmente, contra-ataque, essa é a biopolítica. Diferentemente do biopoder, que é o poder sobre a vida, a primeira é o poder de potência da vida, o poder de sempre resistir a imposições, modelos prontos e acabados. Foucault não constrói um discurso vazio, ele remonta todo o contexto do século XVIII, para mostrar que essas práticas da biopolítica já se mostravam presentes neste período, como ele mesmo afirma: "a fábrica e seus horários durante muito tempo suscitaram uma resistência passiva que se traduziu no fato simplesmente de faltar ao trabalho" (FOUCAULT, 1979, p. 225). Isso mostra que, no século XVIII, mencionado por Foucault como princípio dos poderes sobre o corpo, há seguramente uma resistência a essas normas que visam controlar o corpo, como no caso do estabelecimento dos horários das fábricas. E, assim: "A norma é o 
que pode tanto se aplicar a um corpo que se quer disciplinar quanto a uma população que se quer regulamentar" (FOUCAULT, 1999, p. 302).

A população resiste à aplicação de normas, o que tem muito a ver com o possível conceito de liberdade em Foucault, que, embora não seja o objetivo desta investigação, mas é concomitantemente necessário colocar por sua relação com a biopolítica. Deste modo abordaremos mesmo que brevemente o conceito de "liberdade", sua importância para Foucault, bem como por manter inteira relação com o segundo sentido de biopolítica.

\section{A LIBERDADE COMO POSSIBILIDADE PRESENTE NAS BIOPOLÍ- TICAS DE RESISTÊNCIA}

Poder-se-ia dizer que Michel Foucault foi um pensador que refletiu sobre a liberdade? A partir da leitura de suas obras observa-se o quanto ele se ocupou nos estudos de várias "morais", mas não apenas num estudo descritivo, em que o investigador se considera apenas um mero observador daqueles modos de vida, e sim, nota-se o quanto Foucault se preocupa em refletir sobre a liberdade dessas "morais", ou seja, dos costumes diferentes, inclusive em relação aos diferentes grupos que formavam distintas "morais", principalmente, na cultura greco-romana.

Porquanto havia vários grupos e várias morais dentro do grande Império Romano e isso encheu Foucault de júbilo, isso porque "todo o seu pensamento foi orientado pela concepção radicalmente negadora da tentação do uno" (SOUZA, p. 2). É muito importante frisar essa questão, pois desde o início dos seus estudos, Foucault sempre defendeu um pensamento que afirma o múltiplo, as múltiplas éticas, os modos diferentes de viver que pertencem a cada sociedade. Além disso, Foucault procurou ressaltar a perspectiva daqueles que eram marginalizados nas suas respectivas épocas, por não agirem de acordo com a moral vigente. No artigo intitulado Foucault: o cuidado de si e a liberdade, ou a liberdade é uma agonística, Alípio comenta sobre este aspecto da liberdade, dizendo:

Sabemos que o estudo dessas morais levou Foucault a se ocupar com o tema da ética, da estética da existência, da verdade, do sujeito da ação, do sujeito ético da verdade. Assim leitores, estudiosos, editores, "descobriram" encantados: no Foucault ocupado com as éticas grecoromanas antigas se encontra o pensador da liberdade [...] (SOUZA FILHO, 2011, p. 1).

Foucault surge, então, como aquele que atribui liberdade ao sujeito, que quer fazer com que cada sujeito guie suas vidas, e é principalmente por este motivo que Foucault se admira a ética greco-romana, considerando que nesta sociedade havia uma grande gama de "morais", várias pessoas vivendo de modos diferentes, sem que houvesse repreensão quanto a essas diferenças, cada qual consudindo a sua vida numa aceitação múltipla de costumes diferentes. Para aqueles que ainda são incrédulos, e que pensam que Foucault não abordou o tema da liberdade, Benjamim Julião diz:

É possível vislumbrar a temática da liberdade já nas suas primeiras discussões sobre o poder. O Foucault de Vigiar e Punir é o mesmo da Hermenêutica do Sujeito [...]. E mais: o Foucault da Hermenêutica do Sujeito é o mesmo de Doença mental e Psicologia, na qual movido pela vontade de liberdade, procura fugir das categorizações, das naturalizações do que é construído na cultura (GÓIS FILHO, 2010, p. 35). 
Todavia, isso ainda diz pouco a respeito do que está sendo pesquisado, por isso é importante ainda relembrar a questão que está sendo investigada: a liberdade pode ser concebida como uma possibilidade presente na biopolíticas de resistência? Considerando que a biopolítica encarada como política de resistência pode muito bem ajudar a resolver essa indagação, porquanto é através da utilização de políticas de resistências que se fazem críticas, que se travam lutas, que se exige a efetividade de direitos, todos esses aspectos não deixam de ser um processo de busca pela liberdade. Resistir ao poder que o outro tenta estabelecer é uma forma de limitar o poder do outro e também de procurar inventar a sua própria liberdade. Assim, é através da resistência que se pode exercitar a liberdade, é assim que, segundo a filósofa Judith Revel considera que a biopolítica pode ser entendida também como "expressão de potência da vida face aos poderes" (RAVEL, 2006, p. 53). Uma potência da vida que, aliás, busca sempre a liberdade, que reinventa modos de vida, criando uma "estética da existência".

\section{CONSIDERAÇÕES FINAIS}

Pensar sobre o conceito de liberdade, mesmo que de maneira sucinta, é muito importante, pois mostra que a liberdade se mostra como um jogo de poder, que pode ser vista através das biopolíticas de resistência, na luta pela construção de uma estética da existência. Desse modo pode-se afirmar que a liberdade surge como uma possibilidade presente nas biopolíticas de resistência, possibilidade esta que pode se tornar realidade pela construção de uma estética da existência, que é tornar a vida uma obra de arte, segundo a qual código moral não basta para guiar a vida. A vida, assim como a liberdade, deve ser inventada e reinventada, à medida que não pode haver liberdade com imposições frequentes a partir do outro. A falta de liberdade se transforma sempre em mecanismo de dominação, fazendo com que o sujeito deixe de ser "sujeito" e passe a ser um "objeto", manipulado de forma fácil pelos demais. Por isso, a biopolítica pode ser um instrumento de liberdade em que o sujeito luta e reivindica sua subjetividade própria.

O estudo do conceito de biopolítica mostrou-se muito relevante, porque esclareceu algumas questões que muitas vezes não são levadas em consideração nas obras de Foucault, como, por exemplo, tratar a biopolítica de duas formas, fazendo, assim, uma bipartição: a primeira forma se apresenta como responsável e constituinte do processo econômico e político que se realiza a partir do século XVIII e que culminou no surgimento do liberalismo; e, a segunda forma da biopolítica que se apresenta como política de resistência em prol do indivíduo, que busca, no exercício da liberdade, criar a sua própria subjetividade.

\section{REFERÊNCIAS}

DANNER, Fernando. Cuidado de si e estética da existência em Foucault. In: Filosofazer. Passo Fundo, No 32, jan/jun, 2008. P. 73-79.

FOUCAULT, Michel. O Nascimento da Biopolítica: curso dado no Collège de France. Edição estabelecida por Michel Senellart; sob a direção de François Ewald e Alessandro Fontana; Tradução Eduardo Brandão; revisão da tradução Claudia Berliner. São Paulo: Martins Fontes, 2008.

FOUCAULT, Michel. Em defesa da sociedade. Tradução Maria Ermantina. São Paulo: 
Martins Fontes, 1999. P. 302

FOUCAULT, Michel. Microfísica do Poder. Organização e tradução Roberto Machado. Rio de Janeiro: Ed. Graal, 1979.

GÓIS FILHO, Benjamim Julião. Foucault e a (BIO) Política: Possibilidades e metamorfoses de um conceito. Dissertação de mestrado apresentada em 2010.Disponível em: www.filosofia.cchla.ufrn.br/dissertacoes/benjamim\%20juliao.pdf. Acesso em: 10 de setembro. 2011.

REVEL, Judith. Michel Foucault: Conceitos essenciais. Tradução Maria do Rosário Gregolim, Nilton Milanez, Carlos Piovesani. São Carlos: Claraluz, 2005.

SOUZA FILHO, Alípio de. Foucault: o cuidado de si e a liberdade, ou a liberdade é uma agonística. Disponível em: www.cchla.ufrn.br/alipiosousa/.../FOUCAULT,... Acesso em: 01 de setembro de 2011. 